\title{
Dos desafios aquáticos ao estabelecimento de recordes: aproximação e distanciamento entre práticas esportivas e os rios da cidade de São Paulo (1899-1949)
}

Daniele Cristina Carqueijeiro de Medeiros $^{a, *}$ (D)

\section{Palavras Chave:}

História do esporte; Esportes aquáticos; Natureza; Clubes esportivos.

\begin{abstract}
RESUMO
São Paulo foi fundada entre os rios Pinheiros e Tietê, fundamentais ao crescimento da cidade e berço de inúmeros esportes aquáticos. Entre fins do século XIX e início do XX, os rios testemunham a passagem do sentimento de temor da natureza pelo prazer aliado aos desafios corporais, culminando na prática esportiva. Temos como objetivo entender como a mudança nas atividades oferecidas pelos clubes foi responsável por, em determinado momento, afastar os esportes dos rios. Símbolos de uma natureza que não se submete às mãos humanas, os rios foram substituídos por espaços em que as práticas poderiam ser melhor regulamentadas e controladas. 0 recorte temporal vai de 1899, ano de instalação do primeiro clube, até o fim da década de 1940, com a realização das últimas competições.
\end{abstract}

\begin{abstract}
São Paulo was created in the junction of rivers Pinheiros and Tietê, fundamentals for the development of the city and cradle of a lot of sportif practices. Between the end of the 19th century and the beginning of the 20th, the rivers witness the passage of the fear's feeling of nature for the pleasure, culminating in the sport practice. Our aim is to analyze how the change in the activities offered by the clubs was responsible for take away the sports of the rivers. Symbols of a nature that do not submit to human hands, rivers have been replaced by spaces in which practices could be better regulated and controlled. Our period begins in 1899, year when the first club were installed, and goes until the 40 's, when were realized the last competitions.
\end{abstract}

\section{RESUMEN}

São Paulo fue fundada entre los ríos Pinheiros y Tietê, fundamentales para el crecimiento de la ciudad y cuna de innumerables deportes. Entre finales del siglo XIX y el principio del siglo XX, los ríos testimoniaron el paso del sentimiento de temor de la naturaleza por el placer aliado a los desafíos corporales, culminando em la práctica deportiva. Nuestro objetivo es entender como el cambio en las actividades ofrecidas por los clubes fue responsable de alejar los deportes de los ríos. Símbolos de una naturaleza que no se somete a las manos humanas, los ríos fueron sustituidos por espacios en que las prácticas podrían ser mejor reguladas. El recorte va desde 1899, año de instalación del primer club, hasta el final de la década de 1940, con la realización de las últimas competiciones.

\footnotetext{
a Secretaria Municipal de Educação - Prefeitura Municipal de Campinas, SP, Brasil.
}

\footnotetext{
*Autor correspondente:

Daniele Cristina Carqueijeiro de Medeiros

E-mail: danielemedeiros.ef@gmail.com
} 


\section{INTRODUÇÃO}

Tietê é grande rio de São Paulo, aquêle de que logo nos primeiros contactos com a escola nos falam que não corre para o Oceano [...]. Desta circunstância feliz nasce a glória do rio Tietê, rio paulista, amoroso da terra paulista. Suas águas são nossas amigas, pois ao invés de apressarem sua marcha em busca do mar [...] rasgam distâncias em busca do interior, levando a felicidade e a vida às mais longínquas paragens. [...]. Nas suas águas, milhares de jovens se exercitam diariamente, formando-se colmeias onde os esportes náuticos são a fonte de força e de saúde da juventude paulista (Edital, 1940, p. 1).

Foi preciso um longo percurso na história para que adjetivos como "amoroso" e "amigo" pudessem ser atribuídos a um rio. Desde muito antes do advento da ciência moderna, a humanidade se ocupa em construir compreensões acerca da natureza e seus fenômenos. 0 medo, o entusiasmo, os castigos; depois, a observação, a ciência: as rupturas e continuidades na relação humana com o meio natural não param de se alterar (Lenoble, 1969).

Os rios e, de forma semelhante, os mares passaram por um longo período de reabilitação e deixaram aos poucos de ser locais de perigo e incerteza para tornar-se refúgio de contemplação e, mais tarde, de ação. Foi no século XVIII que lentamente novas compreensões sobre a natureza começaram a ser produzidas, ancoradas principalmente na ideia de que a natureza não mais deveria ser temida, e, sim, dominada (Thomas, 1996). A partir daí, novas sensibilidades foram forjadas, permitindo outros usos e relações com a natureza: nascia então uma concepção de natureza pura e benéfica, que contrastava com os elementos da cidade.

O início do século XX marcou, de forma acentuada no Brasil, uma mudança na relação entre a natureza e a ordem urbana. O acentuado crescimento de cidades como São Paulo acabou por eleger a natureza e seus elementos como contraponto ideal aos "males urbanos", que começam a surgir, efeitos da urbanização e da industrialização (Soares, 2016). Essas transformações marcaram também a relação dessa cidade com os rios, que não ficaram imunes às mudanças ocorridas no período.

Esses rios eram responsáveis, sobretudo, pelo fornecimento de água às casas e às fábricas desde a instalação das primeiras habitações em seu entorno. Entretanto, Gouveia (2016) afirma que, em meados do século XIX, a "providência divina" já não era mais suficiente para a manutenção do abastecimento de água a todos os moradores locais. Os anos que se seguiram marcaram mudanças profundas no curso dos rios aqui estudados, na tentativa de produzir energia, impedir as inundações e afastar a iminente poluição (Jorge, 2006).

É possível associar essas mudanças estruturais àquilo que Sevcenko (1992) chamou de ideal de modernização, pretendida pelas autoridades, pela burguesia, pelos médicos e por todos aqueles que pensavam nas benesses da vida na cidade. Essa modernização não se deu só no âmbito da malha urbana: um sem número de costumes e modos de divertimento foram importados da Europa e incorporados ao cotidiano paulistano, não sem ressignificações e resistências. Em meio a esses elementos, encontrava-se o esporte.

Símbolo de um modo de vida urbano e republicano, o esporte serviria bem aos intentos de uma sociedade brasileira que pretendia se inserir na modernidade. Em países como Inglaterra, França e Estados Unidos, a estruturação do esporte moderno se ligou a elementos como a nova dinâmica dos tempos sociais, o crescimento das cidades, as relações com o corpo. (Guttmann, 2004). Guardando algumas dessas características, os esportes foram incorporados ao cenário das cidades brasileiras desde fins do século XIX, assegurando-se, é claro, as tensões provenientes dos novos sentidos e significados atrelados a essa prática (Gois Junior, 2013; Silva, 2015).

De acordo com autores que se ocuparam da história de São Paulo no início do século $X X$, foi no leito dos rios, mais especificamente do rio Tietê, que diversas práticas esportivas tiveram seu alvorecer na cidade, principalmente aquelas ligadas ao nado e ao remo (Sevcenko, 1992; Jorge, 2006). A literatura aponta que a instalação dos clubes esportivos às margens dos rios a partir de 1899 transformou a forma como eles eram entendidos e experimentados: de espaços de contemplação, tornaram-se espaço de ação. Ainda, é corrente a impressão de que esses espaços - agora esportivos - deixaram de ser utilizados quando a poluição tornou inviável a prática de esportes nas águas desses rios urbanos, que passaram a outros espaços menos suscetíveis às intempéries.

Neste artigo, temos como objetivo analisar as transformações ocorridas nas ações realizadas pelos clubes às margens dos rios que culminaram na consolidação de práticas esportivas. Temos como intuito entender como a mudança nas atividades oferecidas pelos clubes foi responsável por, em determinado momento, afastar as práticas esportivas das águas dos rios Pinheiros e Tietê. Símbolos de uma natureza que não se submete às mãos humanas, os rios foram substituídos paulatinamente por espaços em 
que as práticas poderiam ser melhor regulamentadas e controladas, como piscinas e represas.

É desse universo, dos divertimentos, dos clubes e das práticas esportivas nos rios, que se ocupa esta pesquisa. Considerando a complexa rede de significados presente em nosso objeto, o conjunto diversificado de fontes ancora-se na ampliação da noção de documento histórico (Bloch, 2001). Para tanto, fez-se necessário buscar, em meio à extensa gama de testemunhos históricos, aqueles que nos permitiam analisar as práticas de divertimento e de esportes realizadas nos rios paulistanos. Tomamos como fontes: atas, documentos e registros dos clubes esportivos; legislação sobre os rios; jornais "Gazeta Esportiva" e "Correio Paulistano"; além de outros artefatos da cultura material presentes nos acervos dos clubes aqui analisados. Esta documentação constitui-se como um rico conjunto de fontes que nos permite olhar para as práticas realizadas nos rios a partir de diferentes perspectivas. Por um lado, documentos como estatutos, relatórios e atas nos possibilitam avaliar o que era instituído de forma mais "oficial". Por outro, temos uma série de vestígios que detalham o cotidiano dos clubes através de atividades; festas realizadas e dos embates ideológicos que cercavam suas práticas.

\section{DESAFIAR AS ÁGUAS, REFRESCAR OS CORPOS, DIVERTIR A ALMA}

De acordo com Thomas (1996), as sensibilidades estabelecidas com relação à natureza normalmente se baseavam em uma oposição na qual, de um lado, situavam-se as zonas urbanas, e, de outro, o meio rural ou a natureza das grandes paisagens. Mas como localizar nessas sensibilidades a natureza que perpassa o meio urbano?

Havia uma diferença entre a natureza ajardinada, produzida pelas mãos humanas, e aquela mais rude. Certamente, ainda que engenheiros, sanitaristas e autoridades quisessem transformar os rios aqui estudados em elementos de uma natureza controlada, eles seguiam escorregadios por esses arranjos humanos.

Assim, esse descompasso entre indocilidade do fenômeno natural eartimanhas da engenharia moderna permitia que os rios fossem ainda exóticos em meio ao cenário urbano que se desenhava. Os rios Pinheiros e Tietê, na virada do século $X X$, ao mesmo tempo que atraíam olhares e visitantes, causavam medo e repulsa.

Os passeios logo começaram a fazer parte do bom aproveitamento dos rios e permitiram aos observadores aproveitarem aquele elemento a partir de novos ângulos, promovendo diferentes sensações. Homens e mulheres, vestidos em trajes de passeio, desciam rio afora, em geral conduzidos por barqueiros.
Uma apreciação mais próxima entre a água caudalosa e a pele começava a se estabelecer; o roçar das gotas nos braços e pernas, os aromas existentes no meio do rio e mesmo a relação com os riscos de atravessá-los promoviam novas relações e sensibilidades entre os homens e as mulheres e as águas, outrora percebidas apenas como espaço de transporte, provimento de alimentos ou de energia.

Entretanto, alerta-nos Soares (2016, p. 20), a vida ao ar livre pretendida e proclamada pelas instituições educativas e médicas do período não era uma "valorização das práticas anônimas e ingênuas junto à natureza", esim uma vida "penetrada pela quantificação, pelas medidas, pela duração dos exercícios físicos, bem como de tempos muito preciosos de exposição ao sol e de mergulhos em distintas águas".

Uma natureza que tonificava e fortalecia os corpos dos habitantes das cidades poderia ser aquela proclamada nas vilegiaturas rumo a montanhas, à beiramar ou às estâncias hidrominerais, ou - para aqueles que não poderiam usufruir de tais oportunidades - aquela dos rios que cortavam as cidades. $O$ início do século XX inaugurou, nas páginas dos jornais paulistanos, outros usos das águas dos rios, agora não mais guiados pelo medo e desconfiança, e sim pelo sentimento do desafio.

O jornal "Correio Paulistano" anunciou, em 1898, dois desafios aquáticos, em que os competidores "Nadarão rio abaixo, cahindo ambos na Ponte Grande. Vencido será o que primeiro de parte de fraco, sahindo da água" (Natação, 1898, p. 2). De acordo com o jornal, esse desafio gerava grandes apostas entre os partidários de cada nadador, tornando famosas as disputas.

Ainda que essas competições tivessem um caráter bastante desvinculado das práticas regulamentares esportivas, havia o interesse de que "estes desafios [fossem] o inicio da fundação de um club de natação, tanto assim que este útil sport, é dos mais despresados pela nossa sociedade" (Natação, 1898, p. 2).

Foi com esse novo pensamento que clubes de natação e remo começaram a surgir nas margens dos rios aqui estudados: em 1889, o Esperia foi inaugurado ao lado da Ponte Grande, mesmo ano em que o Germânia nascia às margens do rio Pinheiros. Com esses clubes, novas formas de utilizar o rio emergiam, mudando o cenário desses locais.

\section{“O QUE É NECESSARIO PARA PODER SER UM ESPORTISTA?" - A INSTALAÇÃO DOS CLUBES PAULISTANOS}

O surgimento dos clubes esportivos paulistanos às margens dos rios sintetizou as transformações que 
vinham ocorrendo na forma de entender os usos possíveis dos rios e as novas formas de divertimento que poderiam ser ali proporcionadas. As transformações que lentamente ocorriam nas sensibilidades a respeito das águas foram aceleradas com a promoção de novos exercícios e atividades dentro do escopo dos clubes.

É possível afirmar que a instalação de tais clubes no início do século XX na cidade de São Paulo colocou os rios, e mais especificamente suas águas, em evidência. $\mathrm{O}$ olhar dos paulistanos, especialmente aqueles que participavam das provas e eventos foi transformado, e os rios passaram de desafiantes elementos da natureza a parceiros de eventos e provas.

O clube Esperia teve sua fundação em 1899, promovida por um grupo de imigrantes italianos que tinha a intenção de fomentar a prática do remo na cidade de São Paulo. No mesmo ano, um grupo de alemães se reunia para a criação do Sport Club Germania, nascido para a prática de futebol, mas que, após a fundação da nova sede, passou a se ocupar da prática do remo. Outros clubes fundados ainda nos primeiros anos do século XX foram o Clube de Regatas São Paulo (dissuadido em 1913), o Clube de Regatas Tietê e a Associação Atlética São Paulo, fundados respectivamente em 1907 e 1914 (Zoccoli, 1934, p. 48).

$\mathrm{O}$ aumento no interesse pelos clubes e seus serviços oferecidos fez com que, nos primeiros anos de existência, essas instituições procurassem definir quais eram seus objetivos, competências e regras. Era preciso ensinar aos novos associados como ser esportivo, os benefícios da nova cultura física que passava a ser promovida, como se comportar durante um jogo, quais as nuances positivas do esporte que deveriam ser incentivadas e quais as práticas rejeitadas.

Uma preocupação constante dos clubes era com o desenvolvimento da juventude frequentadora dos espaços sociais e esportivos por eles disponibilizados. De acordo com a revista comemorativa do Sport Club Germania em seu 25o aniversário (25 annos..., 1924, p. 6), oprimeiro lema do clube, anotado na ata de fundação, continha a seguinte frase: "A força da juventude garante o futuro dos povos". Para os membros do clube, o fortalecimento do corpo e do caráter dos jovens era um dos pilares de existência da agremiação.

A cultura física ${ }^{1}$ que os clubes procuraram propagar era, em sua maioria, pautada na realização de esportes, em geral competitivos. Entretanto, promover essas práticas não se limitava tão só à "prática pela prática" dos esportes; era preciso, pelo contrário, incutir as

1 Entendemos que o conceito de cultura física permite a compreensão de inúmeros discursos e práticas relativos ao corpo, que vão desde relações sociais, econômicas e políticas até aquelas ligadas a questões morais e éticas (Kirk, 1999; Scharagrodsky,2014). vantagens morais e higiênicas da prática esportiva e, acima de tudo, sua capacidade de moldar positivamente o caráter dos defensores das agremiações.

Em matéria intitulada "O que é necessário para poder ser um esportista" (1936, p. 7), o Clube de Regatas Tietê transcreveu um "estatuto do esportista", divulgado pelo Comitê Olímpico Internacional, em que deveria se responder a algumas perguntas. De acordo com a reportagem, era preciso que todo tieteano refletisse sobre tais questionamentos antes de tomar parte nas competições ou na torcida:

\section{ÉS UM ESPORTISTA?}

Como jogador

- Jogas por amor ao esporte?

- Jogas para tua turma e não para ti mesmo?[...]

- Sabes ganhar sem alarde e perder sem lamurias?

- Então vaes por um bom caminho para ser esportista

- Como espectador

- Recusas applaudir o bom jogo de teus contrários?

- Desejas que ganhem os teus, ainda que não mereçam? [...]

Em caso affimativo não és um esportista. Procura chegar a sê-lo (O que é necessário.., 1936, p. 7).

As indicações dos clubes eram bastante objetivas: os indivíduos que não se adequavam às regras e à moral estabelecida pelos eventos esportivos não deveriam tomar nas competições o lugar daqueles que seguiam as regras à risca.

Os clubes paulistanos, de forma geral, procuravam associar suas práticas esportivas aos ditames científicos, higiênicos e educativos, engrandecendo, sobretudo, sua luta para a manutenção da prática esportiva na cidade:

Poucas organizações esportivas vicejam com a flama idealista de trabalhar pelo bem da coletividade. E o bem da coletividade, este caso, significa contribuir para que se generalize a pratica do esporte, tão necessária à higiene do espirito e ao revigoramento físico. A pratica do esporte, tendo por lêma não apenas o divertimento, a despreocupação, mas em obediencia às regras de uma perfeita educação física - reunindose o agradável ao útil - é muito pouco adotada. De forma que, espetáculo como êsse que oferece o Clube de Regatas Tietê é raro e merece ser posto sempre em evidencia (O esporte pelo esporte, 1940, p. 1).

Ao analisarmos os regulamentos, atas de fundação e reportagens escritas nas revistas dos clubes, é possível perceber quais eram as intenções existentes por trás do estabelecimento das atividades desenvolvidas pelas entidades náuticas 
aqui estudadas. Percebemos logo que havia a noção de que as práticas tinham total relação com a ideia de desenvolvimento físico e esportivo dos sócios, além de relações íntimas com o melhoramento da raça, desenvolvimento da saúde e da higiene e fortalecimento do corpo.

Entretanto, como nos alerta Chartier (1991), há uma diferença entre as práticas e suas representações: enquanto representações nos documentos escritos, é possível perceber uma miríade de intenções associadas às práticas realizadas nesses espaços. Ou seja, cabe questionar: ao analisar as práticas, teriam elas os mesmos objetivos e seriam regidas pelas mesmas lógicas?

É certo que, ao longo das primeiras décadas do século $\mathrm{XX}$, as maiores aparições dos clubes aqui elencados foram nas páginas dos jornais ligadas às festas de bailes. Cada agremiação náutica promovia seus eventos, ou todas juntas organizavam grandes festas, como era o caso do "Banho à fantasia", festa de carnaval organizada nas águas do Tietê (Um banho á phantasia, 1923, p. 9). Entretanto, as competições e festivais também adentravam o escopo de práticas promovidas pelas entidades esportivas.

As primeiras competições relatadas nos jornais foram realizadas em 1904, com disputas de nado nas águas do Tietê (Rowing, 1904, p. 4). Em 1907, outro tipo de desafio anunciado no jornal teve lugar no rio: uma competição de pulos. As regras do certame foram assim instituídas:

Cada concorrente deve dar, alternadamente, cinco pulos de cima duma prancha convenientemente instalada sobre o rio a uma altura de dois metros e meio da superfície da água. [...] [são] considerados vencedores aquelles dois que maior numero de votos obtiverem no jury que para esse fim será constituído (Pulos no rio..., 1907, p. 4).

Os eventos promovidos pelos clubes nos primeiros anos de existência abarcavam competições mais tradicionais, como remo e natação, e outras menos comuns, como a competição de pulos no Clube de Regatas São Paulo, no mesmo ano (Rowing, 1904, p. 3). O programa também era variado e contava com distintas atividades:

O programma está attrahentissimo, pois conta de quatro bem equilibrados pares de regatas, entre escaleres, canóas, baleeiras e embarcações de 1 só remador, corridas: a pé, com obstáculos, uma interessante corrida com ovo na colher entre senhoritas, esgrima, gynastica, e outros interessantes sports.
A descrição das atividades realizadas não nos parece, a princípio, o programa de uma competição esportiva. Foi ao longo do tempo que as competições passaram a ser descritas com mais detalhes no jornal, especialmente o remo, que já começava a ser dividido em distintas categorias. Todavia, ainda que algumas especificações começassem a ser feitas, é possível perceber que os primeiros festivais realizados pelos clubes aqui analisados possuíam bem pouco das conhecidas características que definem os esportes, como a especificidade das regras, a importância dos tempos obtidos em esportes de marca, a seleção de árbitros e a premiação comum a todas as provas. Mesmo as atividades selecionadas para fazer parte do programa eram bem pouco ligadas àquilo que posteriormente convencionou-se chamar de esporte. Porém, a esportivização das práticas, característica marcante da cultura física do século XX, não tardaria a adentrar os programas dos clubes paulistanos ora estudados, assim como ocorrido em outras cidades brasileiras (Moraes e Silva, 2015).

\section{A ESPORTIVIZAÇÃO DAS PRÁTICAS AQUÁTICAS}

Os esportes, como definem Gutmann (2004), Bourdieu (2003) e Vigarello (2008), são práticas que tem como características a racionalização, a especialização e a burocratização, que os aproximam de regras cada vez menos flexíveis e mais universais. Com isso, o tempo, e, para esportes como a natação e o remo, o tempo transformado em recorde, tornou-se uma variável cada vez mais determinante, devendo ser medido, quantificado e divulgado. Tudo aquilo que atrapalhasse o controle das variáveis esportivas foi, pouco a pouco, sendo substituído por aparatos de melhor tecnologia e espaços nos quais elas pudessem ser mais bem determinadas (BOURDIEU, 2003). Essas características da esportivização transformaram as relações entre as práticas aquáticas e os rios paulistanos.

Com o passar do tempo, os eventos programados pelos clubes passaram a contar com outros elementos e aportes. Em primeiro lugar, a criação de ligas e federações acabou por transformar a forma como os eventos eram programados. Em 1907, foi criada em Santos a Federação Paulista das Sociedades de Remo, com a presença de cinco clubes. Essa federação era responsável por operacionalizar e promover todas as competições que envolvessem esportes aquáticos. A especialização dos esportes e das regras fez com que essa federação fosse dividida, surgindo dela a Federação Paulista de Natação e a Federação Paulista de Remo (O Tietê-SP vence...,1936, p.11).

Ao mesmo tempo que federações mais especializadas eram criadas, as críticas às provas aquáticas realizadas nos rios apareciam com mais 
frequência nas revistas e jornais esportivos. Em comentários sobre os Jogos Olímpicos de Los Angeles, o técnico de remo do C.R. Tietê, Americo Garcia, avaliou que a cidade de São Paulo preparava mal seus competidores no remo, "por ser este praticado num local improprio e condenável para os typos de barcos internacionais" (Garcia, 1935, p. 15).

Além das críticas à falta de controle com relação às provas de remo, as provas de natação e polo aquático realizadas nos rios também eram condenadas. Em matéria publicada no jornal "A Gazeta", o mau desempenho em competições nacionais e internacionais dos paulistanos foi atribuído à falta de piscinas na cidade:

Um dos motivos do estacionamento do bello esporte da natação entre nós é o facto de não podermos controlar os tempos realizados $e$ estabelecer uma tabella de recordes, como fazemos no athletismo. [...]

Parece incrível que uma cidade tão adeantada como a nossa, sob todos os pontos de vista, não tenha ainda uma piscina para a prática de natação e do polo aquatico (Tempos e recordes..., 1925, p. 13).

Memo as provas emblemáticas realizadas em água doce sofriam problemas ocasionados pelo "excesso de natureza" dos rios. Em 1939, a prova Johnny Weissmuller, de travessia da cidade no rio Tietê organizada pelo Clube de Regatas da Penha, foi cancelada pela falta de chuvas:

Parece curioso que fatores ocasionais possam determinar o desfecho de um acontecimento; mas, força é convir que dependendo êle de circunstâncias de ordem natural, fora da vontade das gentes, verificase que a realização da prova "Johnny Weissmuller" depende tão só deum maior volume de agua no rio Tietê, ora em vasante absoluta (As chuvas designarão..., 1939, p. 13).

Embora os eventos realizados pelos clubes paulistanos fossem todos no rio Tietê, e as provas que envolviam os clubes do litoral fossem realizadas na enseada do Vallongo, em Santos, bastou que a Federação Paulista de Remo fosse criada para que os eventos oficiais fossem transferidos para um local considerado mais adequado para as competições de remo: a represa de Santo Amaro. Já em 1931, com a realização de uma regata patrocinada pela Força Pública nesse local, a revista "Cho-Cho", publicação do Clube de Regatas Tietê, considerou que "local mais apropriado não se encontraria, visto ser idêntico aos locaes onde são realisados os campeonatos brasileiros e internacionaes" (Regatas em Santo..., 1931, p. 1). Logo, esse local permitiria que os competidores paulistanos disputassem em igualdade páreos nacionais e mesmo olímpicos.

Com relação à prática da natação e do polo aquático, era imperativa a construção de piscinas na cidade. A diretoria do clube Esperia, em 1931, iniciava os estudos ligados à engenharia para a instalação da piscina do clube, que os associados "há tanto tempo anciavam, [...] para desfructar do prazer de natação num local adequado" (Edital, 1931, p. 1). Entretanto, antes das obras do Esperia serem finalizadas, o Clube de Regatas Tietê viu sua obra vultosa passar a fazer parte da sede social: a piscina do clube ficou pronta em junho de 1934, e o evento contou até com a produção de um número especial da revista do clube.

Nessa revista, diversos artigos sobre a instalação da piscina foram produzidos em relação às obras, às dimensões e aos gastos. A questão esportiva também entrou em pauta, e as benesses proporcionadas pela prática em um ambiente controlado foram exaltadas:

É desnecessário ocupar espaço e tempo em minucias de sem valor, pois é suficiente lembrar que ela foi plasmada na [piscina] de Los Angeles onde se disputaram os últimos torneios olímpicos. De fáto, elas são identicas em suas dimensões. [...]

A magnifica picina do Tietê constitue, pois, uma das maiores contribuições ao desenvolvimento dos esportes aquáticos em nossa terra (Lorenzo, 1934, p. 16).

A piscina instalada proporcionaria também outro benefício com relação à participação em torneios e campeonatos: a melhoria na técnica das braçadas. Após a inauguração da piscina do clube Esperia, houve, de acordo com a revista do clube, um aumento significativo no número de sócios que se interessaram pelas aulas de natação, já que "a aprendizagem na piscina torna[va]se de uma facilidade surprehendente, mesmo porque offerec[ia] ao insipiente nadador maiores garantias do que um rio ou mesmo um lago" (Aprenda a nadar..., 1934 , p. 19). Para auxiliar os novatos, o clube contratou um instrutor, responsável por ensinar os novos praticantes as primeiras braçadas, e um treinador, para as turmas que desejavam competir:

[...] o Esperia contratou um technico japonez, o sr. Kanichi Sato, que acompanhou a delegação do seu paiz á penúltima olympiada. Esse technico, de reconhecida capacidade, preparará as turmas esperiotas que desejarem tomar parte em torneios (Aprenda a nadar, 1934, p. 19). 
Era fremente a especialização das práticas esportivas aquáticas na cidade de São Paulo, assim como no resto do mundo. O imperativo dos recordes, outrora combatido pelos clubes brasileiros (A mania dos recordes..., 1932, p. 14), passou a dominar as narrativas sobre essas práticas. Os discursos sobre a natação e o remo começavam a se munir da melhoria dos instrumentos de medição, dos barcos e da técnica das braçadas para se equiparar à prática realizada em outros lugares do mundo. Assim, as provas realizadas nos rios ficaram obsoletas, ainda que tentassem se adequar às novas lógicas impostas a esses esportes.

A "Travessia de São Paulo à Nado", prova instituída em 1928 que tinha como objetivo a travessia do rio Tietê por nadadores e nadadoras, foi invadida pela "febre dos recordes", ainda que realizada nos rios. Em 1935, a travessia teve um novo recorde histórico: João Havelange, nadador do Fluminense, obteve a marca de 45'38" (Novo recorde..., 1935, p. 2). Entretanto, a instituição de recordes nos rios era bastante questionável: a cada ano, os números obtidos eram diferentes por conta da cheia dos rios, da velocidade da correnteza. Em 1940, por exemplo, "graças ás condições excepcionais do Rio Tietê, Heimuth von Schuetz marcou 43 minutos e 11 segundos" (Heimuth von Schuetz..., 1940, p. 16). Entre 1935 e 1940, nenhum recorde havia sido quebrado; isso não pela técnica dos nadadores, mas sim pelas más condições do rio.

A criação das piscinas e, mais tarde, da raia olímpica da USP (1973) acabou rompendo os últimos elos dos clubes com os rios que os banhavam. Com a possibilidade de medir e quantificar as provas em locais mais controlados pela mão humana, os clubes acabaram virando as costas para os rios, e agora, em vez de propor ações que tivessem como pano de fundo o Pinheiros e o Tietê, eles se voltavam para seu interior e construíam muros para separar-se desse lugar "bravio e inquieto".

\section{CONSIDERAÇÕES FINAIS}

O Plano de Avenidas, projeto de Prestes Maia para a solução dos problemas ligados às cheias dos rios e à circulação de pessoas e mercadorias, começou a sair do papel em sua primeira administração como prefeito, em 1938. A partir desse momento, começam a ser colocadas em prática transformações que mudariam sobremaneira a relação com as margens dos rios paulistanos, afastando cada vez mais as pessoas e aproximando os carros. A retificação do Tietê, proposta por esse plano, implicaria mudanças para os clubes, apontada em reportagem na revista do Tietê (O que a retificação..., 1940, p. 9). Entretanto, a maior reclamação dos clubes não se dava mais na malha esportiva, e sim na diminuição dos terrenos, que seriam perdidos para a construção das marginais. A questão esportiva nos rios não estava mais em pauta naquele momento.

A poluição foi outro elemento presente na década de 1940. A "Travessia de São Paulo à Nado" deixou de ser realizada em 1944, com a alegação de que um dos competidores havia contraído tifo nas águas do Tietê e que, da forma como estavam as águas, seria impossível dar continuidade a esse evento (Jorge, 2006, p. 13).

Assim, é visível um movimento de ascensão e morte das práticas corporais nos rios paulistanos. A natureza dos rios foi a priori instigante e açodou provas, desafios aquáticos, passeios, regatas, torneios de nado. 0 objetivo, nesse primeiro momento, era transpassar suas águas e sair ileso. Entretanto, esse mesmo elemento desafiador acaba sendo um empecilho na realização de provas que tinham como objetivo medir outras grandezas que não o contentamento relativo ao enfrentamento das águas.

Foi possível perceber, portanto, que as transformações relacionadas aos rios, como a instalação de marginais e a crescente poluição, não foram as únicas razões do abandono das práticas esportivas em suas águas. A especialização da cultura física, transformada cada vez mais em esporte, também proporcionou um distanciamento entre os clubes e as águas do Pinheiros e do Tietê.

\section{REFERÊNCIAS BIBLIOGRÁFICAS}

25 annos do Sport Club Germânia. 25 Jahre - Sport Club Germânia, 1924:6.

A mania dos recordes empolga a natação. A Gazeta. 1932 Apr 18;Caderno Esportivo:14.

Aprenda a nadar ou, se já sabe, melhore a sua technica. Revista Mensal Clube Espéria, Feb/Mar 1934;6(2):19.

As chuvas designarão as datas da "Johnny Weissmuller". A Gazeta. 1939 Nov 6;Caderno Esportivo:13.

Bloch ML. Apologia da história, ou, O ofício de historiador. Rio de Janeiro, RJ: Zahar; 2001.159 p.

Bourdieu P. Questões de sociologia. Lisboa: Fim de século; 2003. p. 136-153.

Chartier R. O mundo como representação. Estudos Avançados. 1991;5(11):173-191.

Kirk D. Physical Culture, Physical Education and Relational Analysis. Sport, Ed. and Soc. 1999; 4(1): 63-73.

Lorenzo, J. A piscina do C.R. Tietê no esporte nacional. Revista do Clube de Regatas Tietê. Jun 1934:16.

Edital. Revista Mensal do Clube Espéria. Fev 1931;3(28):1.

Edital. Tietê - Orgão oficial do C.R. Tietê. 1940 Jan;1(1):1.

Garcia A. O remo nas Olympiadas de Los Angeles. Tietê - orgam official do C.R. Tietê- SP. 1935 Jun;1(3):15.

Gois Junior E. O esporte e a modernidade em São Paulo: práticas corporais no fim do século XIX e início do XX. Movimento. 2013 Oct/Dec;19(4):95-117.

Gouveia ICMC. A cidade de São Paulo e seus rios: uma história repleta de paradoxos. Confins Revista Franco-Brasileira de Geografia [Internet]. 2016 Jul;(27). Disponível em: https:// journals.openedition.org/confins/10884. 
Guttmann A. From ritual to record. New York: Columbia University Press; 2004. 224 p.

Heimuth von Schuetz vence a XIV Travessia de São Paulo a Nado!. A Gazeta. 1940 Feb 26;Caderno Esportivo:13.

Jorge J. Tiete, o rio que a cidade perdeu: o Tiete em São Paulo 1890-1940. São Paulo: Alameda; 2006. 232 p.

Lenoble R. História da ideia de natureza. Lisboa: Edições 70; 1969. $378 \mathrm{p}$.

Moraes e Silva M. Comportamentos urbanos e esportes: contribuições para a esportivização do Turf e da Pelota Basca em Curitiba (1899-1905). Lic. 2015; 18(3): 86-115.

Natação. Jornal Correio Paulistano. 1898 Feb 25:2.

Novo recorde da prova: 45"38" de Havelange e Define. Mais de 50 nadadores abaixo do antigo recorde. A Gazeta. 1935 Feb 25; Caderno Esportivo:2.

O esporte pelo esporte. Tietê - Orgão oficial do C.R. Tietê. 1940 Jun/Jul;1(5):1.

O que a retificação do Tietê póde significar para os clubes da Ponte Grande. Revista do Clube de Regatas Tietê. Mar 1940;1(3):2.

O que é necessário para poder ser um esportista?. Tietê Revista dos Tieteanos. Mar 1936;1(6):7.

O tietê-SP vence a 1 a regata da Federação Paulista do Remo. A Gazeta. 1936 Jun 20;Caderno Esportivo:11.

Pulos no rio Tietê. Jornal Correio Paulistano. 1907 May 2:4.

Regatas em Santo Amaro. CHO-CHO: folha clandestina no seio do C.R. Tietê. 1931 Nov 22;1(11):1.

Rowing. Jornal Correio Paulistano. 1904 Aug 14:4.
Rowing. Jornal Correio Paulistano. 1904 Oct 13:3.

Scharagrodsky PA. Palabras preliminares. In: Miradas médicas sobre la cultura física en Argentina (1880-1970). Buenos Aires: Prometeo; 2014. p.9-12.

Sevcenko N. Orfeu extático na metrópole: São Paulo, sociedade e cultura nos frementes anos 20. São Paulo: Companhia das Letras; 1992. $390 \mathrm{p}$.

Silva CF. Os esportes náuticos e aquáticos no Rio Grande do Sul/RS: esportivização e contatos culturais nos clubes. Rio Grande do Sul. Tese [Doutorado em Ciência do Movimento Humano] - Universidade Federal do Rio Grande do Sul, 2015

Soares CL. Três notas sobre natureza, educação do corpo e ordem urbana (1900-1940). In: Soares CL. Uma educação pela natureza: a vida ao ar livre, o corpo e a ordem urbana. Campinas: Autores Associados; 2016. p. 9-45.

Tempos e recordes em natação. A Gazeta. 1925 Feb 19:13.

Thomas K. O homem e o mundo natural: mudanças de atitude em relação a plantas e aos animais (1500-1800). São Paulo: Companhia das Letras; 1996. 544 p.

Um banho á phantasia. A Gazeta. 1923 Feb 9:9.

VIgarello G. Treinar. In: História do corpo: as mutações do olhar - o século XX. Direção de Alain Corbin, Jean-Jacques Courtine, Georges Vigarello. Petrópolis: Vozes; 2008. p. 197-250.

Zoccoli C. O Tietê de hoje e de amanhã. Revista do Clube de Regatas Tietê. Jun 1934:48. 